\title{
Indian Ocean surface winds from NCMRWF analysis as compared to QuikSCAT and moored buoy winds
}

\author{
B N Goswami and E N RAJAGOPAL ${ }^{2}$ \\ ${ }^{1}$ Centre for Atmospheric and Oceanic Sciences, Indian Institute of Science, Bangalore 560 012, India. \\ ${ }^{2}$ National Centre for Medium Range Weather Forecasting, Department of Science and Technology, Mausam \\ Bhavan, Lodi Road, New Delhi 110 003, India.
}

\begin{abstract}
The quality of the surface wind analysis at the National Centre for Medium Range Weather Forecasts (NCMRWF), New Delhi over the tropical Indian Ocean and its improvement in 2001 are examined by comparing it with in situ buoy measurements and satellite derived surface winds from NASA QuikSCAT satellite (QSCT) during 1999, 2000 and 2001. The NCMRWF surface winds suffered from easterly bias of $1.0-1.5 \mathrm{~ms}^{-1}$ in the equatorial Indian Ocean (IO) and northerly bias of $2.0-3.0 \mathrm{~ms}^{-1}$ in the south equatorial IO during 1999 and 2000 compared to QSCT winds. The amplitude of daily variability was also underestimated compared to that in QSCT. In particular, the amplitude of daily variability of NCMRWF winds in the eastern equatorial IO was only about $60 \%$ of that of QSCT during 1999 and 2000. The NCMRWF surface winds during 2001 have significantly improved with the bias of the mean analyzed winds considerably reduced everywhere bringing it to within $0.5 \mathrm{~ms}^{-1}$ of QSCT winds in the equatorial IO. The amplitude and phase of daily and intraseasonal variability are very close to that in QSCT almost everywhere during 2001. It is shown that the weakness in the surface wind analysis during 1999 and 2000 and its improvement in 2001 are related to the weakness in simulation of precipitation by the forecast model in the equatorial IO and its improvement in 2001.
\end{abstract}

\section{Introduction}

The northern Indian Ocean (IO) is characterized by a strong annual cycle of surface winds associated with the Asian monsoon while the equatorial IO is characterized by a semiannual cycle. The special character of the surface winds in the IO is responsible for a mean sea surface temperature (SST) distribution that is different from the Pacific and the Atlantic, with cooler water in the west and warmer water in the east (McPhaden 1982; Rao et al 1989). The annual mean zonal wind in the central equatorial IO is rather small (about $1.5 \mathrm{~ms}^{-1}$ averaged between $40^{\circ} \mathrm{E}-100^{\circ} \mathrm{E}, 2^{\circ} \mathrm{S}-2^{\circ} \mathrm{N}$ ) while the amplitude of the annual and semiannual components is about $2 \mathrm{~ms}^{-1}$. The zonal wind stress in this region is westerly from March to October and largest during spring and fall that drive the equa- torial spring and fall jets in the IO (Wyrtki 1973). The equatorial jets deepen the thermocline in the east contributing to the maintenance of warm SST in the eastern IO. The equatorial jets also influence the seasonal cycle of circulation in the Bay of Bengal (McCreary et al 1993; Vinayachandran et al 1996) via coastal Kelvin waves. The interannual variations of the jets also determine interannual changes in equatorial IO SST associated with the dipole mode (Murtugudde et al 2000). The duration and strength of westerly wind stress determines the nature of the equatorial jets. As the mean westerly wind stress is rather small, a relatively small uncertainty in the winds can lead to significant error in simulation of seasonal circulation in the north IO and its interannual variability. Most ocean model studies of the IO (McCreary et al 1993; Murtugudde et al 1998, 1999, 2000;

Keywords. Equatorial Indian Ocean; ocean surface forcing; NCMRWF analysed winds; scatterometer winds. 
Vinayachandran et al 1998; Schiller et al 2000) use monthly mean surface winds to study the seasonal cycle and interannual variability. However, the amplitude of intraseasonal variability in zonal wind is $2-3 \mathrm{~ms}^{-1}$ over the equatorial IO, as large as the seasonal variations (Goswami et al 1998, Sengupta et al 2001). Such intraseasonal oscillations may influence the equatorial jets, the equatorial Rossby waves and the poleward propagating coastal Kelvin waves when the jets encounter the eastern boundary. Therefore, accurate high frequency surface winds in the equatorial IO are not only required to understand the intraseasonal variability in the ocean but also to understand seasonal and interannual variations.

Operational analysis products such as the National Centers for Environmental Prediction/ National Center for Atmospheric Research (NCEP/NCAR) reanalysis (Kalnay et al 1996) provide high frequency surface wind fields going back several decades in time while the European Center for Medium Range Weather Forecasts (ECMWF) reanalysis (ERA, Gibson et al 1997) provide similar data for a period of 15 years. The high temporal resolution and global coverage of the reanalysis products make them attractive for forcing ocean models to study ocean circulation and thermodynamics. A possible weakness of reanalysis or any other operational analysis products is that systematic errors of the assimilation model influence the analysis in data sparse regions. Most atmospheric general circulation models (AGCMs) have significant systematic errors in simulating the strength and annual march of the tropical rain band specially in the Indian monsoon region (Saji and Goswami 1997; Gadgil and Surendran 1998). As the surface winds over the tropical oceans are primarily driven by tropospheric heating associated with deep convection, model biases in simulating precipitation may significantly influence surface wind analyses over data sparse regions such as the equatorial Indian Ocean (Saji and Goswami 1997). A recent study (Goswami and Sengupta 2003) compared NCEP/NCAR reanalyzed surface winds with in situ observations and satellite derived surface wind products over the Indian Ocean and concluded that the reanalysis not only underestimates the time mean but also the intraseasonal oscillations in the eastern equatorial Indian Ocean.

The National Centre for Medium Range Weather Forecasting (NCMRWF), New Delhi, regularly produces daily surface wind analysis that may be useful for studies of climate variability and air-sea interactions. To establish the goodness of the surface wind analysis of NCMRWF, it is important to compare it with in situ observations and other reliable surface wind products. In this study, we examine the daily surface wind from NCMRWF for its fidelity in capturing the seasonal and intraseasonal variability in the IO in general and the equatorial IO in particular. We compare the NCMRWF surface winds with two independent sets of wind observations. Recent satellite derived winds give reasonable spatial coverage on daily time scale. The Sea-Winds scatterometer onboard NASA's QuikSCAT satellite provides daily ocean wind vectors from July 19th, 1999 till the present. During this period, the Department of Ocean Development (DOD) of India had a set of moored met-ocean buoys operating in the north Indian Ocean. We carry out a limited comparison between available wind measurements from the buoys and the NCMRWF winds, followed by a comparison of NCMRWF and QuikSCAT wind fields in the tropical IO. In section 2 , the data used in this study are described. The annual cycle and intraseasonal variability of NCMRWF surface winds are compared to those of QuikSCAT winds in section 3. Significant reduction of bias in NCMRWF wind speed over the equatorial IO during 2001 as compared to those during 2000 and 1999 is highlighted in this section. Possible cause for the bias in the analyzed surface winds during 1999 and 2000 is investigated and a likely reason for improvement during 2001 is indicated in section 4 . The results are summarized in section 5 .

\section{Data used}

The study uses daily zonal $(u)$ and meridional $(v)$ winds at $10 \mathrm{~m}$ height derived from NCMRWF analysis (hereafter referred to as NC winds) for the period 1999 to 2001. The NCMRWF employs a 6-hourly intermittent Global Data Assimilation System, (GDAS) and utilizes all conventional and non-conventional data received through GTS at Regional Telecommunication Hub (RTH), New Delhi. Non-conventional data include cloud motion vectors (CMVs) from INSAT, GMS, GOES and METEOSAT satellites, NOAA satellite temperature profiles and three layer precipitable water content, surface wind information from ERS-2 satellite etc. The analysis scheme is based on minimization of a generalized cost function using the Spectral Statistical Interpolation (SSI) technique (Parrish et al 1997; Rizvi et al 2000). The GDAS includes a weather prediction model with horizontal resolution of $\mathrm{T} 80$; the spatial resolution of the analyzed winds is about $1.5^{\circ}$ in both latitude and longitude in the tropics. The winds at $10 \mathrm{~m}$ height are extrapolated from the lowest model level winds using ratio of exchange coefficients (at $10 \mathrm{~m}$ and lowest model level) as weighting function. 
The Sea-Winds scatterometer (Freilich et al 1994) was launched on the NASA QuikSCAT in June 1999. Wind speed and direction are inferred from measurement of microwave backscattered power from a given location on the sea surface at multiple antenna look angles. Measurement of radar backscatter are obtained from a single location at the sea surface from multiple azimuth angles as the satellite travels along its orbit. Estimate of vector winds are derived from these radar measurements over a single broad swath of $1600 \mathrm{~km}$ width centered around the satellite ground track. Scatterometer wind retrievals are calibrated to the neutral stability wind at a height of $10 \mathrm{~m}$ above the sea surface (Chelton 2001). We obtained the $0.25^{\circ} \times 0.25^{\circ}$ gridded QuikSCAT Level 3 data between July 19, 1999 and December 31, 2001 from the Jet Propulsion Laboratory's SeaWinds project (http://podaac.jpl.nasa.gov/quikscat/). The level 3 data have been created using the Direction Interval Retrieval with Threshold Nudging (DIRTH, Stiles 1999) algorithm. Separate maps are provided for ascending and descending passes. The data also contained several classes of rain flags indicating possible contamination of QuikSCAT observations based on rain estimates from three other satellites that are in operation simultaneously with QuikSCAT. All rainflagged observations were eliminated and we combine observations from ascending and descending passes in the rain free region to obtain daily maps. Finally, a three-day running mean is used to obtain nearly complete spatial coverage. This three-day wind product is referred to as QSCT winds in the text. The superiority of the QuikSCAT coverage compared to previous scatterometers is discussed in detail by Schlax et al (2001). Chelton et al (2001) carried out a comparison of 3-day mean QSCT wind speed with 3day mean wind speed measured from the eastern Pacific TAO buoys under neutral stability conditions with the 3 -month data from 21st July to 20 th October, 1999. The mean and root mean squared (rms) difference from about 1700 collocated observations were found to be $0.74 \mathrm{~ms}^{-1}$ (TAO higher than QSCT) and $0.71 \mathrm{~ms}^{-1}$ respectively. These differences are likely to be partly due to differences in sampling of TAO and QSCT.

The deep sea moored buoys of the National Data Buoy Program (NDBP) of DOD measure several near surface meteorological and oceanic variables (Rao and Premkumar 1998) including wind speed and direction at $3 \mathrm{~m}$ height every three hours. Based on the length of data available with minimum gaps, three deep sea buoys, one in the Bay of Bengal and two in the Arabian Sea are selected for our study. The Bay of Bengal buoy (DS3) was located at $13^{\circ} \mathrm{N}, 87^{\circ} \mathrm{E}$ during 1999 and at $12.15^{\circ} \mathrm{N}, 90.75^{\circ} \mathrm{E}$ during 2000 and 2001 . One Ara- bian Sea buoy (DS1) is located at $15.5^{\circ} \mathrm{N}, 69.25^{\circ} \mathrm{E}$ while the other (DS2) is located at $10.65^{\circ} \mathrm{N}, 72.5^{\circ} \mathrm{E}$. Each three-hourly wind observation is a 10-minute average of wind speed and direction sampled at $1 \mathrm{~Hz}$ by a cup anemometer with vane. The stated accuracy of the wind speed measurements is 1.5\% of the full scale $\left(0-60 \mathrm{~ms}^{-1}\right)$ i.e., $0.9 \mathrm{~ms}^{-1}$. The buoy data have proved to be extremely useful in validating reanalysis and satellite products (Sengupta et al 1999; Senan et al 2001). The buoy winds at $3 \mathrm{~m}$ height are extrapolated to $10 \mathrm{~m}$ height using a power law (Panofsky and Dutton 1984). To understand the differences between the $\mathrm{NC}$ and QSCT winds, we wanted to examine differences between pentad precipitation analysis from the Climate Prediction Center Merged Analysis of Precipitation (CMAP) and $\mathrm{NC}$ analyzed precipitation. However, accumulated precipitation from 6-hour analysis were not saved by NC. We use 24-hour prediction of precipitation by the NC as an approximate representation $\mathrm{NC}$ analysis of precipitation. The CMAP pentad analysis uses the same algorithm and data sources as the monthly analysis of Xie and Arkin (1996), and is based on a blend of rain gauge data and five different satellite estimates of precipitation using infrared and microwave sensors.

To compare the NC winds with another analyzed product, we also collect daily zonal and meridional winds from NCEP/NCAR reanalysis (NRA) for the period 1999 to 2001. The NRA uses the GDAS and an observation base as complete as possible (Kalnay et al 1996). The weather prediction model used in NRA has a horizontal resolution of T62 giving a spatial resolution of the NRA winds of about $1.875^{\circ}$ in longitude and $1.9^{\circ}$ in latitude in the tropics.

\section{Results and discussions}

We compare the NC and QSCT wind speed with in situ measurements from moored buoys at one location in the central Bay of Bengal and two locations in the eastern Arabian Sea. The buoy data are not continuous at any location. There were 435 , 779 and 306 days of buoy data available during 1999, 2000 and 2001 respectively. All the available buoy data from all three locations and corresponding $\mathrm{NC}$ winds at grid points closest to the location of the buoys were collected for 1999, 2000 and 2001. Scatterplots of buoy and NC zonal and meridional winds are shown separately in figure 1(a). The rms differences for zonal and meridional winds are shown in each panel. The least square linear fit (with slope $m$ and intercept $c$ ) is also plotted in each panel. It may be noted that both zonal and meridional winds had a large negative bias (NC 
U
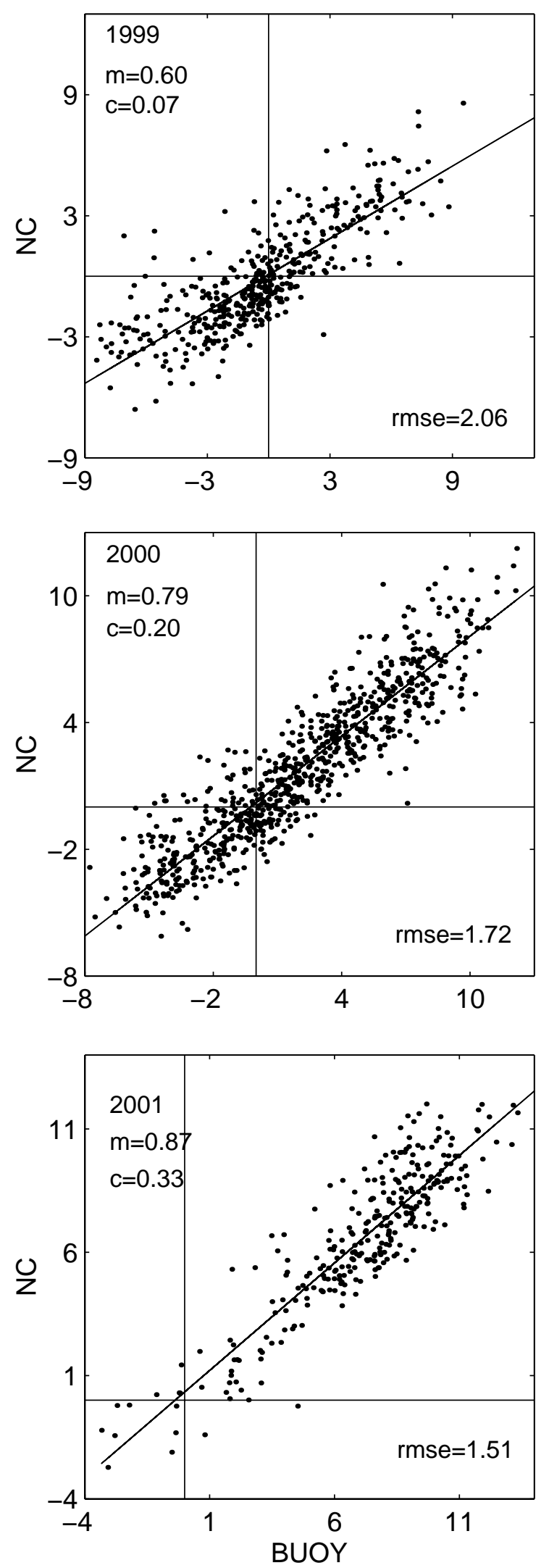

V
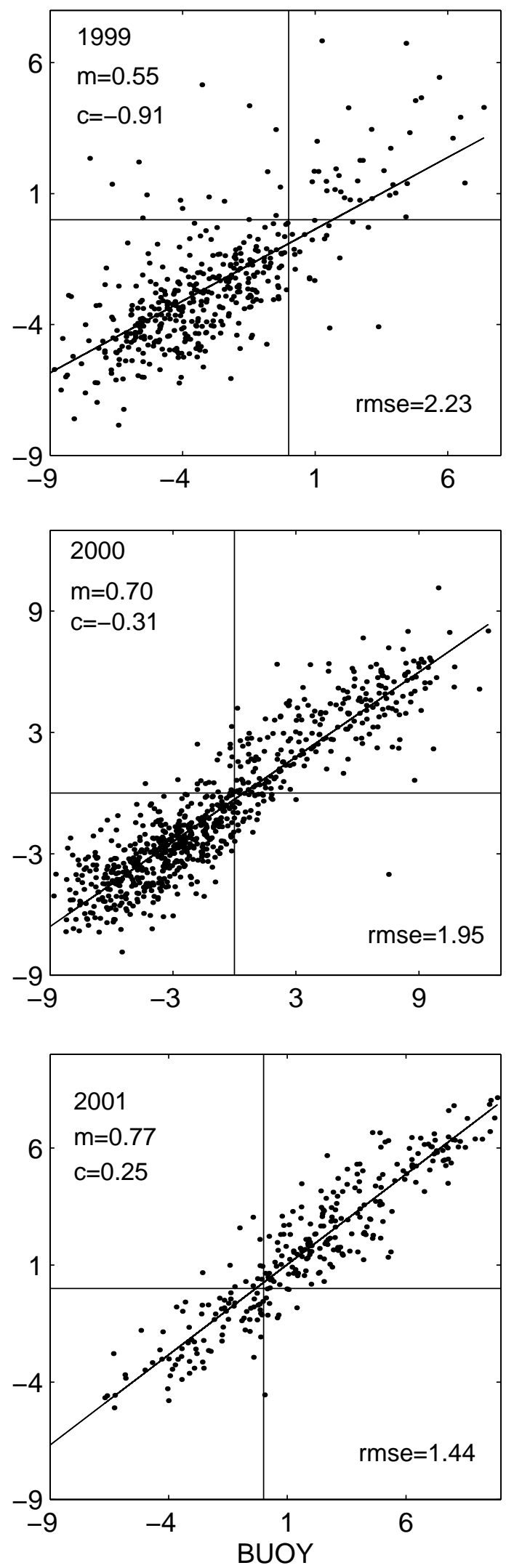

Figure 1(a). Scatter plot between zonal $(U)$ and meridional $(V)$ winds $\left(\mathrm{ms}^{-1}\right)$ from NC and buoys for 1999,2000 and 2001. All the available buoy data from three buoy locations each year and collocated NC winds are plotted. The rms difference is shown in each panel. The least square fit is also plotted and the slope $(m)$ and intercept $(c)$ of the fitted line are also shown. 

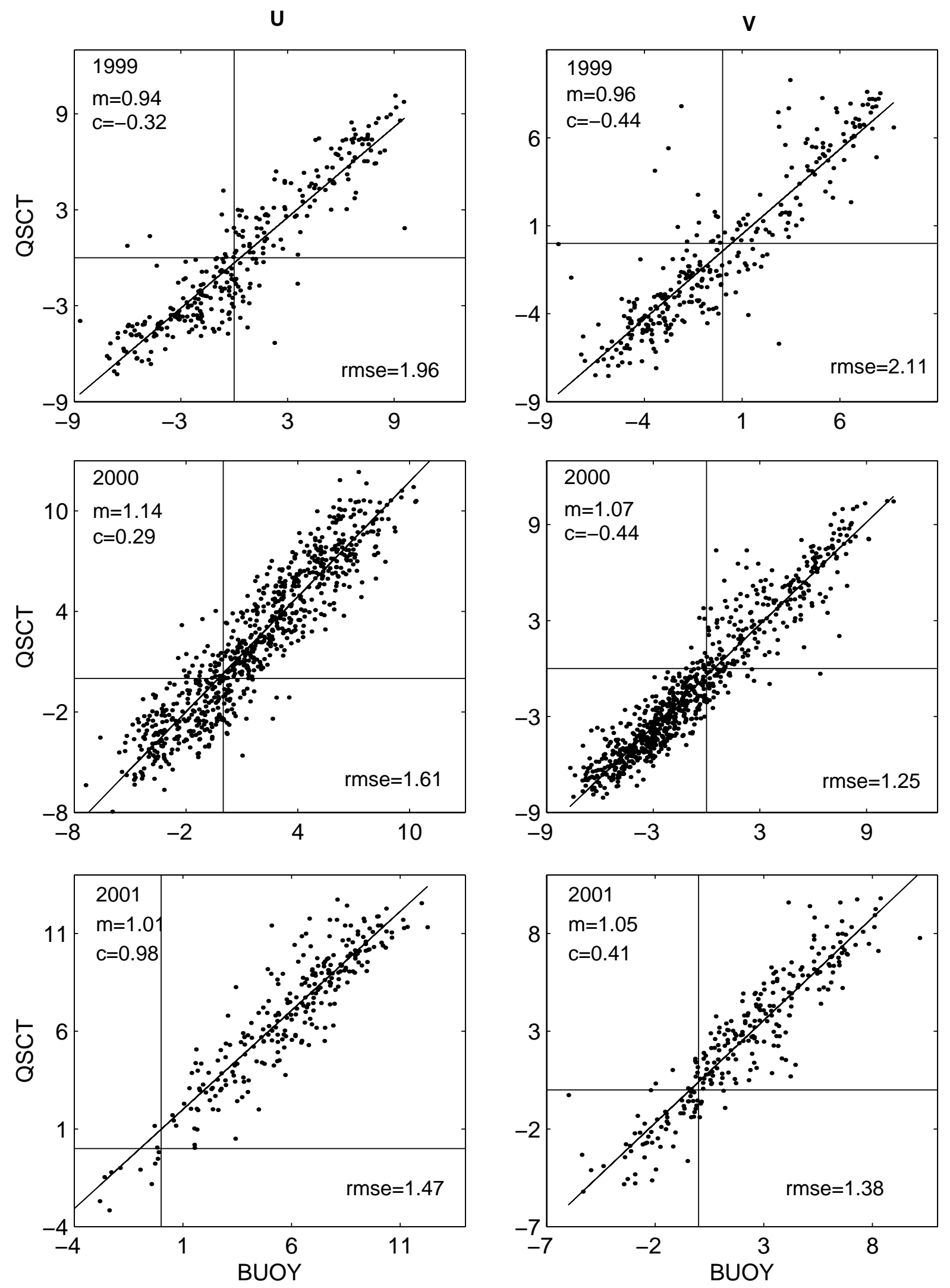

Figure 1(b). Same as (a) but between QSCT and buoy winds. 


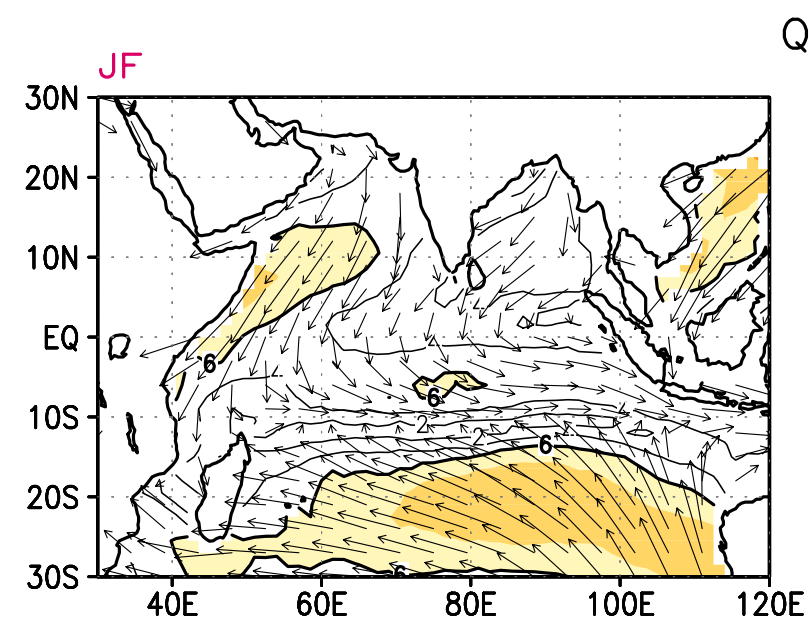

QSCT

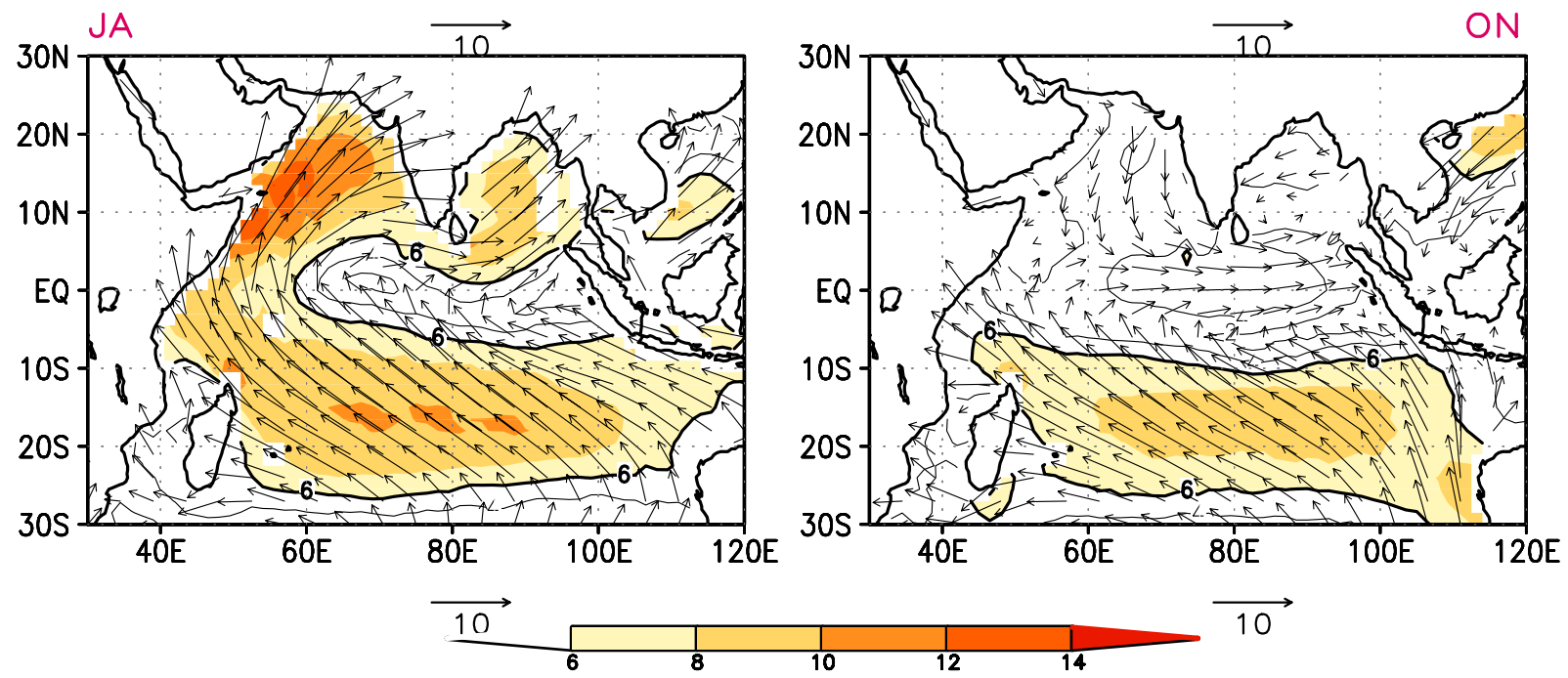

Figure 2. Bimonthly mean wind vectors and isotachs $\left(\mathrm{ms}^{-1}\right)$ from QSCT for January-February (JF), April-May (AM), July-August (AG) and October-November (ON). Isotachs greater than $6 \mathrm{~ms}^{-1}$ are shaded.

weaker than buoy) during 1999 which was reduced marginally in 2000 . The bias in zonal winds is significantly reduced in 2001. It is also noted that the rms difference between NC and buoy winds has slowly decreased from 1999 to 2001. Scatterplots of zonal and meridional winds from QSCT and buoy for the same period are also plotted in figure 1(b). The slope of the fitted curve for both zonal and meridional winds is very close to one in all three years. Thus, the QSCT winds do not have appreciable bias with respect to the in situ observations at the buoy locations. The rms differences between QSCT and buoy winds are also smaller than those between NC and buoy winds.

\subsection{The annual cycle}

In this section, we compare the annual cycle of NC surface winds with that of QSCT. As QSCT winds are at a much finer horizontal grid, they are re-gridded to a $1.5^{\circ} \times 1.5^{\circ}$ latitude-longitude grid to facilitate quantitative comparison with NC winds. The annual cycle of QSCT wind vectors and wind speed is shown in figure 2. Mean winds are averages over corresponding months of 2000 and 2001. In addition to winter (JanuaryFebruary) and summer (July-August), we show spring (April-May) and fall (October-November) winds to illustrate that the mean zonal winds in the equatorial $\mathrm{IO}$ east of $50^{\circ} \mathrm{E}$ are westerly during these two periods of the year. Averaged over July and August, the maximum wind speed in the Somali jet is about $13 \mathrm{~ms}^{-1}$ located approximately at $59^{\circ} \mathrm{E}$ and $12^{\circ} \mathrm{N}$. The vector wind differences between NC and QSCT (NC-QSCT) for JulyAugust and October-November, 1999 are shown in figure 3 indicating the bias of the $\mathrm{NC}$ winds during 1999. Since QSCT winds are available only from July 1999, bias of NC winds during the first half of 1999 could not be shown. Bimonthly mean 


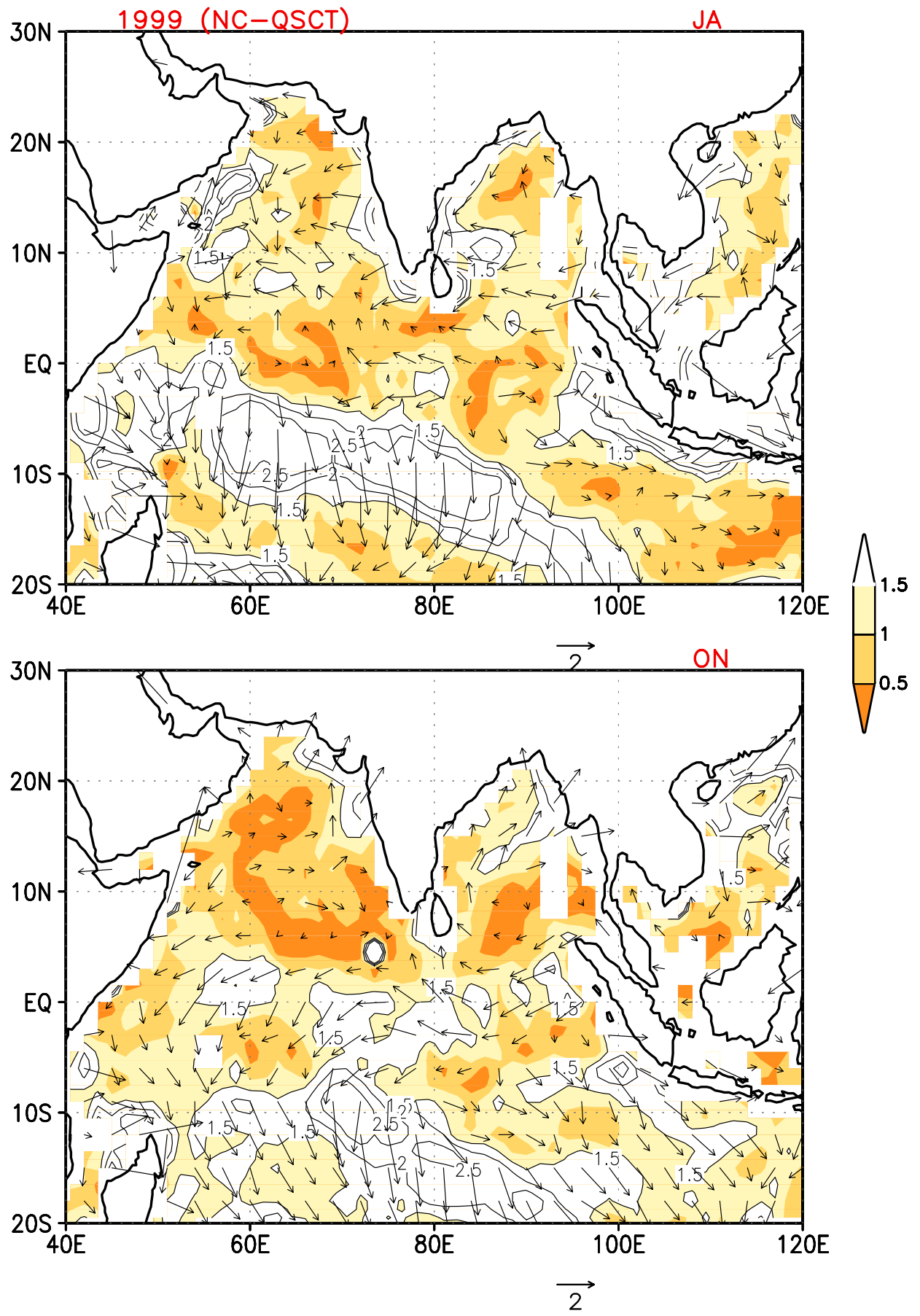

Figure 3. Vector wind bias of NC with respect to QSCT (NC-QSCT) for the bimonthly periods of JA and ON for 1999. Since the QSCT data are available only from July 1999, bias in the other months could not be calculated this year. Isotachs less than $1.5 \mathrm{~ms}^{-1}$ are shaded.

vector wind difference between $\mathrm{NC}$ and QSCT winds for January-February (JF), April-May (AM), July-August (JA) and October-November (ON) during 2000 and 2001 are shown in figures 4 and 5 respectively. In the equatorial IO, the NC has a tendency to have significant easterly bias $\left(1.0-1.5 \mathrm{~ms}^{-1}\right)$ during 1999 and 2000 which is considerably reduced during 2001. The largest wind speed bias of $2-2.5 \mathrm{~ms}^{-1}$ occurs in the southern equatorial $\mathrm{IO}$ between $5^{\circ} \mathrm{S}$ and $20^{\circ} \mathrm{S}$ during 1999 as well as in 2000. This large bias essentially represents much weaker NC meridional winds compared to QSCT in the southern equatorial IO trade wind belt. It is interesting to note that the bias of the NC winds is considerably smaller in 2001 over most of the basin barring a few small pock- 


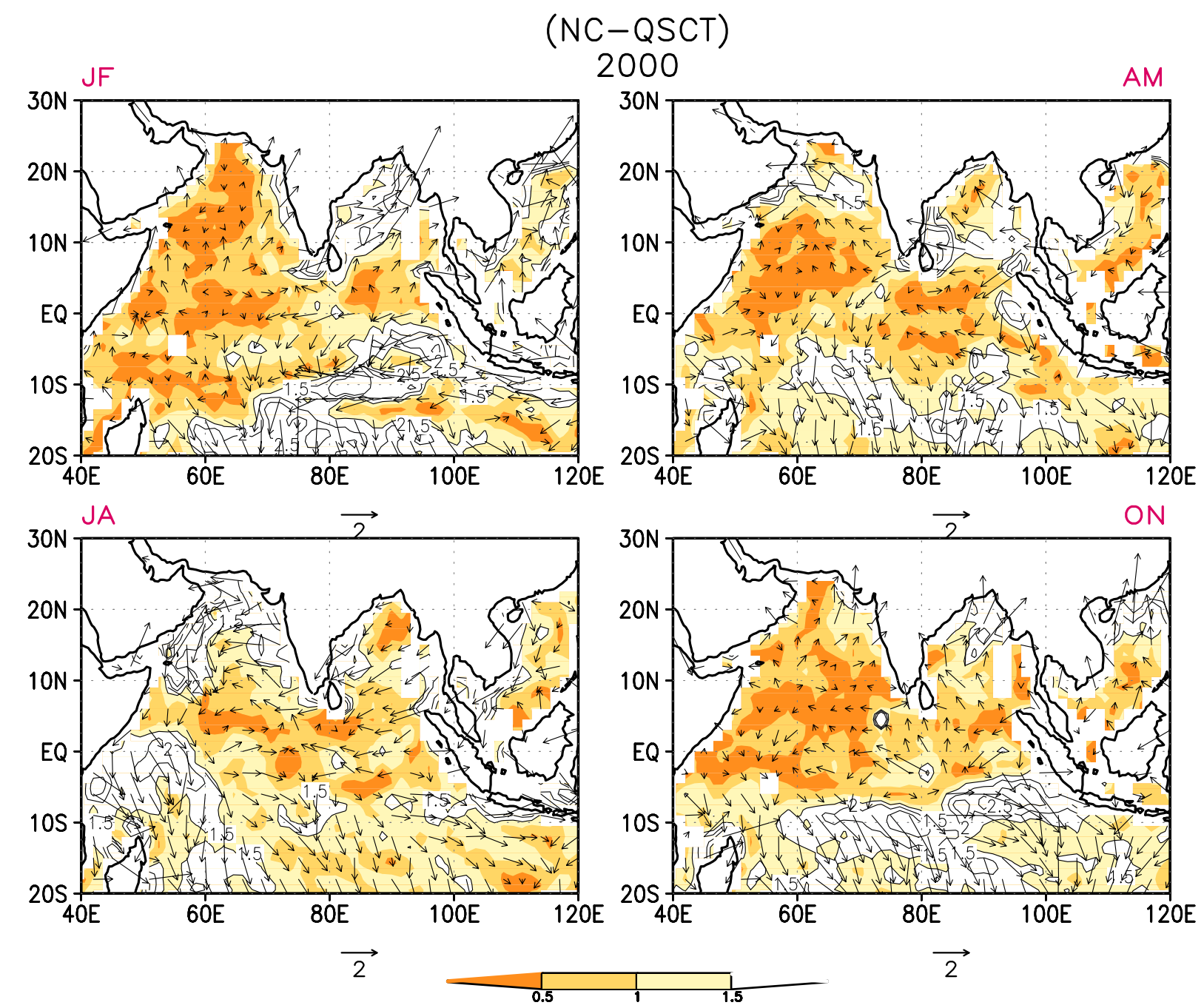

Figure 4. Similar to figure 3 but for 2000. Bias for all four bimonthly periods shown in figure 2 are plotted.

ets. This improvement in bias of $\mathrm{NC}$ winds during 2001 is further illustrated in figure 6 , where wind speed averaged over $70^{\circ} \mathrm{E}-100^{\circ} \mathrm{E}, 5^{\circ} \mathrm{S}-5^{\circ} \mathrm{N}$ for the three years are shown for NC as well as QSCT. The mean bias is shown for each year. It is clear that NC significantly underestimated the wind speed over this region during 1999 and 2000. However, during 2001 the $\mathrm{NC}$ winds are very close to observation (QSCT) over this region with a mean bias of less than $0.3 \mathrm{~ms}^{-1}$. It is also noted that both the amplitude and the phase of the intraseasonal variability is well captured by the NC winds during 2001. As mentioned earlier, Goswami and Sengupta (2003) have shown that NCEP/NCAR reanalysis (NRA) also underestimates the wind speed in the eastern equatorial IO. In an attempt to examine whether the bias in the NRA surface winds improved in 2001, the NRA wind speed averaged over the same region as in figure 6 are compared with those of QSCT in figure 7. The bias of NRA winds during 1999 and 2000 are similar to those of $\mathrm{NC}$ winds during those years. While the bias of NC winds is significantly reduced during 2001, it still remains high for NRA winds. Thus, the reduction of bias in NC winds during 2001 represents an improvement in the NCMRWF analysis system.

\subsection{Daily and intraseasonal variability}

Daily anomalies are constructed after removing the annual cycle (sum of annual mean and first three harmonics) each year from each field. The standard deviation (SD) of daily wind speed anomalies during summer (June-September) of 2000 and 2001 for QSCT are shown in figure 8(a and c) while the ratio between $\mathrm{SD}$ of $\mathrm{NC}$ and QSCT daily anomalies are shown in figure $8(\mathrm{~b}$ and $\mathrm{d})$. The largest amplitude of daily anomalies is $2-2.5 \mathrm{~ms}^{-1}$ over the south equatorial IO, South China Sea and eastern 


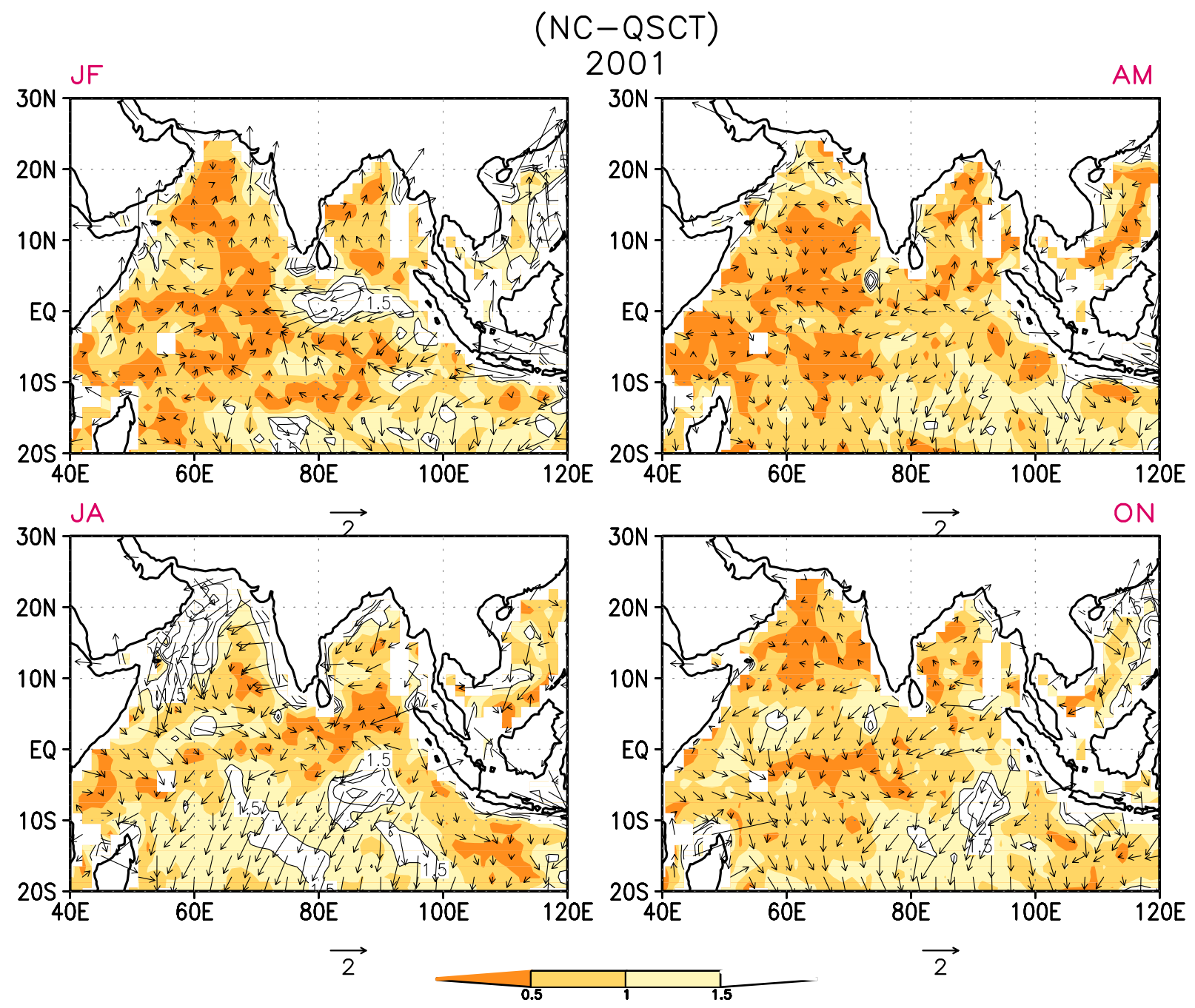

Figure 5. Similar to figure 4 but for 2001.

equatorial IO. The amplitude of daily variations of $\mathrm{NC}$ wind speed in the Bay of Bengal and parts of Arabian Sea is about $80 \%$ of that in QSCT in 2000 (figure 8b) while in the equatorial $\mathrm{IO}$, it is about $60 \%$ of that in QSCT. Thus, the amplitude of daily variability is underestimated by $\mathrm{NC}$ in a large part of the IO. It is interesting to note that this ratio of SD is nearly one almost everywhere in 2001 (figure 8d) showing significant improvement in representing the daily variability by $\mathrm{NC}$ in 2001. The correlation between daily anomalies of $\mathrm{NC}$ and QSCT wind speed during summer of 2000 and 2001 are shown in figure 9. The correlation is poorest along most of the equatorial belt during the summer of 2000. Not only is the amplitude of the daily anomalies weaker in $\mathrm{NC}$ over the equatorial IO, they are also not in phase with QSCT anomalies during 2000. The correlation between NC and QSCT wind speed anomalies improves significantly in 2001 with high correlation $(>0.8)$ covering a much larger area and weaker correlation $(<0.6)$ covering a much smaller area in the equatorial IO. The amplitude (figure 8d) as well as the phase (figure 9 , lower panel) of daily variations are better represented by NC during 2001 compared to 2000 or 1999. There is a small region in the eastern equatorial IO where the correlation between $\mathrm{NC}$ winds and QSCT are small even during 2001 (figure 9, bottom panel). This appears to be in contrast to figure 6 (bottom panel), where the $\mathrm{NC}$ winds averaged over a larger region in the equatorial IO seem to be very well correlated with QSCT winds. To investigate this further, $\mathrm{NC}$ wind speed anomalies averaged over $70^{\circ} \mathrm{E}-100^{\circ} \mathrm{E}, 5^{\circ} \mathrm{S}-5^{\circ} \mathrm{N}$ are correlated with QSCT anomalies averaged over the same region. It is found that the correlation between the two during 2000 was 0.74 while that during 2001 was 0.90 . These correlations are much larger than average of point correlation in the area during 2000 as well as 2001. This indicates that spatial averag- 

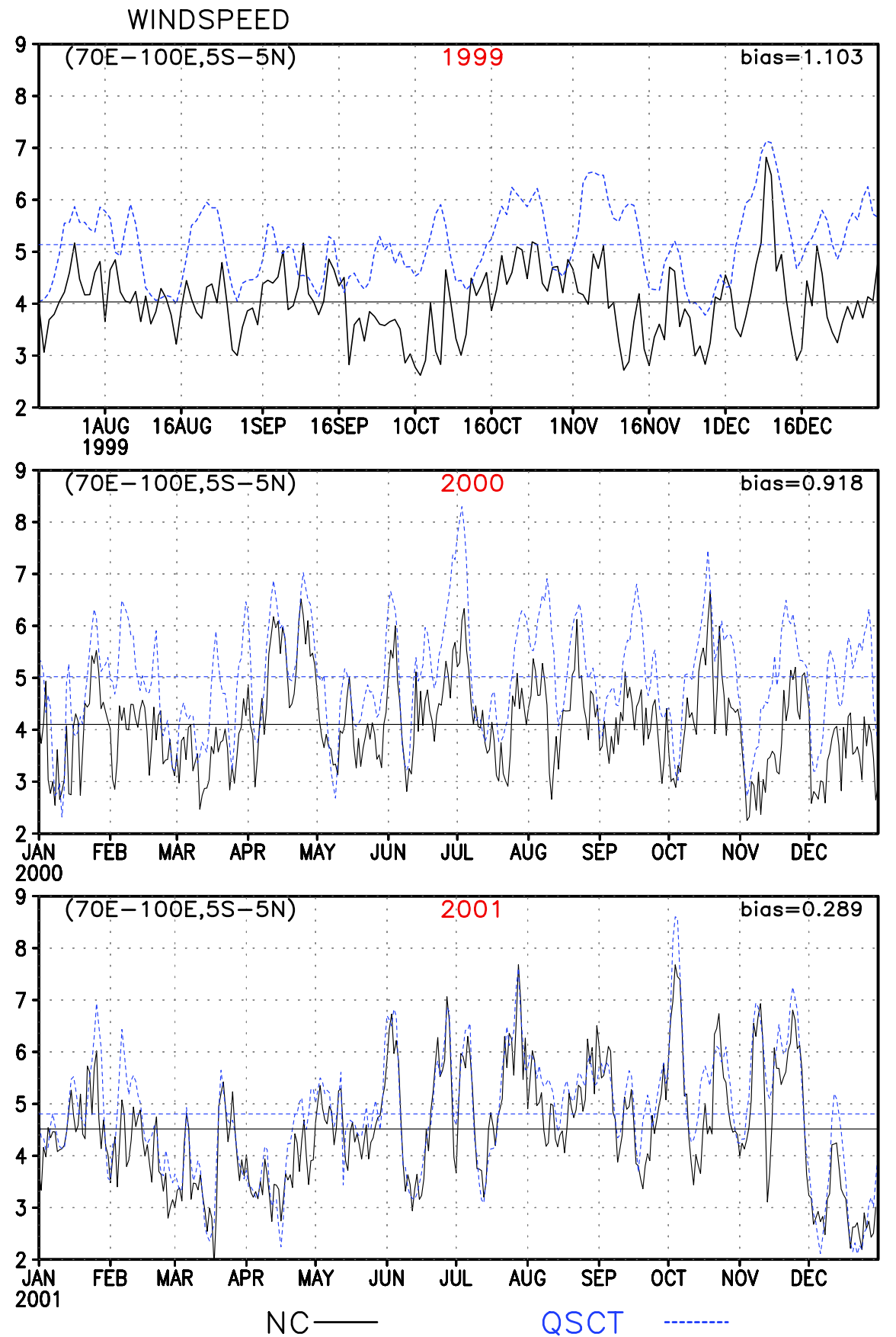

Figure 6. Comparison of wind speed $\left(\mathrm{ms}^{-1}\right)$ averaged over the eastern equatorial $\mathrm{IO}\left(70^{\circ} \mathrm{E}-100^{\circ} \mathrm{E}, 5^{\circ} \mathrm{S}-5^{\circ} \mathrm{N}\right)$ from $\mathrm{NC}$ (solid) and QSCT (dashed) separately for 1999, 2000 and 2001. Time mean of each time series is shown by solid or dashed horizontal lines respectively. Wind speed bias is indicated in each panel.

ing reduces the phase incoherence between $\mathrm{NC}$ and QSCT winds, more so in 2001 than in 2000.

\section{Diagnosis of the wind bias and its improvement}

Why does NC significantly underestimate surface winds in the equatorial IO and south equatorial
IO during 1999 and 2000? What leads to significant improvement of this bias during 2001? Surface winds in the tropics are driven partly by deep tropospheric heating associated with tropical convection (Gill 1980) and partly by surface pressure gradients associated with SST gradients (Lindzen and Nigam 1987). Since seasonal mean SST gradients in the IO are rather weak, surface winds in this region are likely to be driven primarily by the 

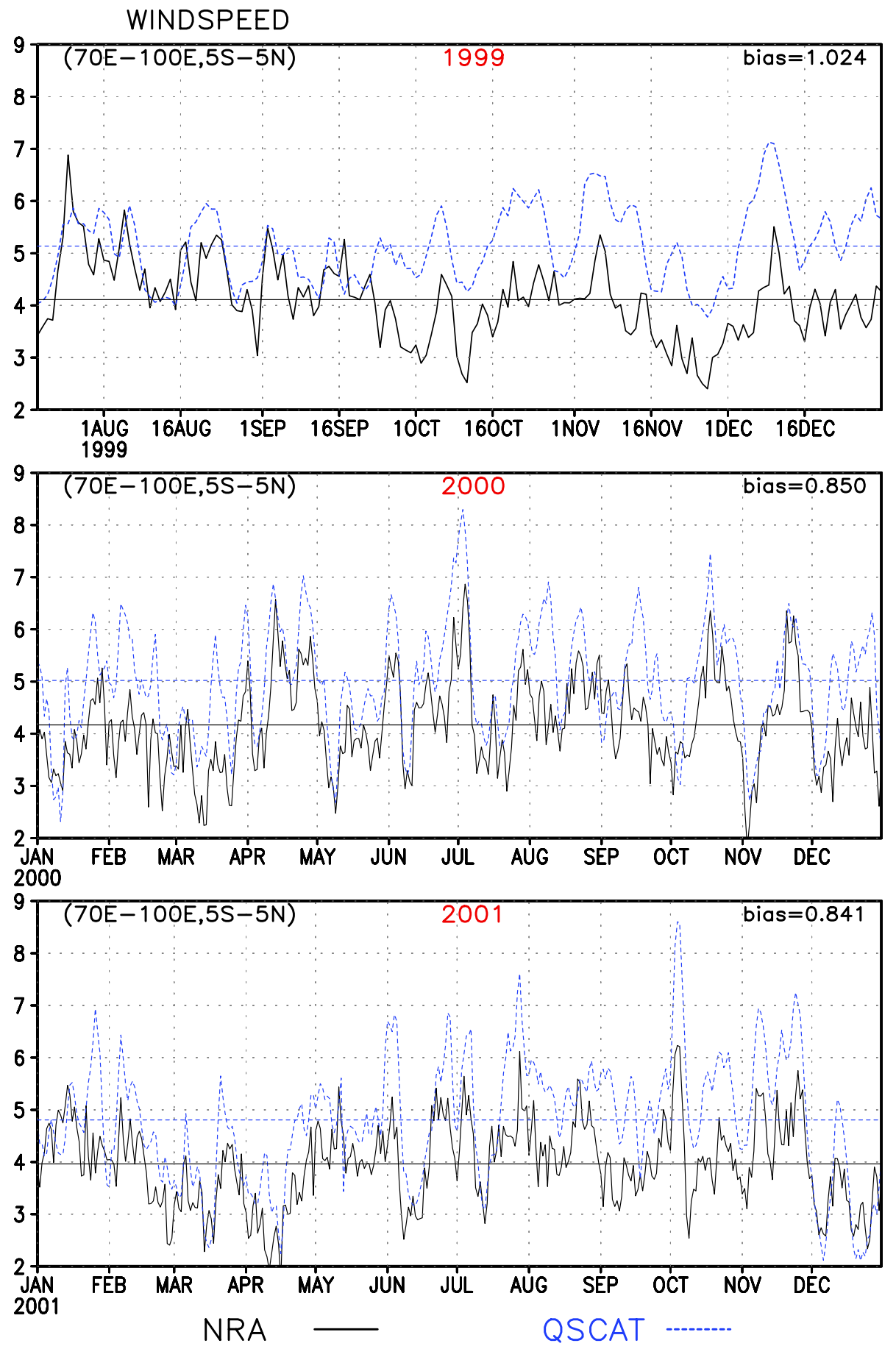

Figure 7. Same as figure 6 but for NCEP/NCAR reanalyzed (NRA) winds and QSCT winds.

elevated heating associated with tropical rainfall (Chiang et al 2001). Therefore, the bias in surface winds in NC is likely to be related to the bias in analysis of precipitation by NC. To test this hypothesis, we compare NC precipitation analysis with observed precipitation. For observed precipitation, we use CMAP. The analysis of precipitation essentially depends on short forecasts of the assimilation model. As precipitation analysis was not saved as such in NC, we use 24-hour prediction of precipitation by the NC model as approximate representation of precipitation analysis. Bimonthly mean difference between $\mathrm{NC}$ and CMAP precipitation is plotted in figure 10 for 2000 and in figure 11 for 2001. It is interesting to note that during 2000, NC significantly underestimates 


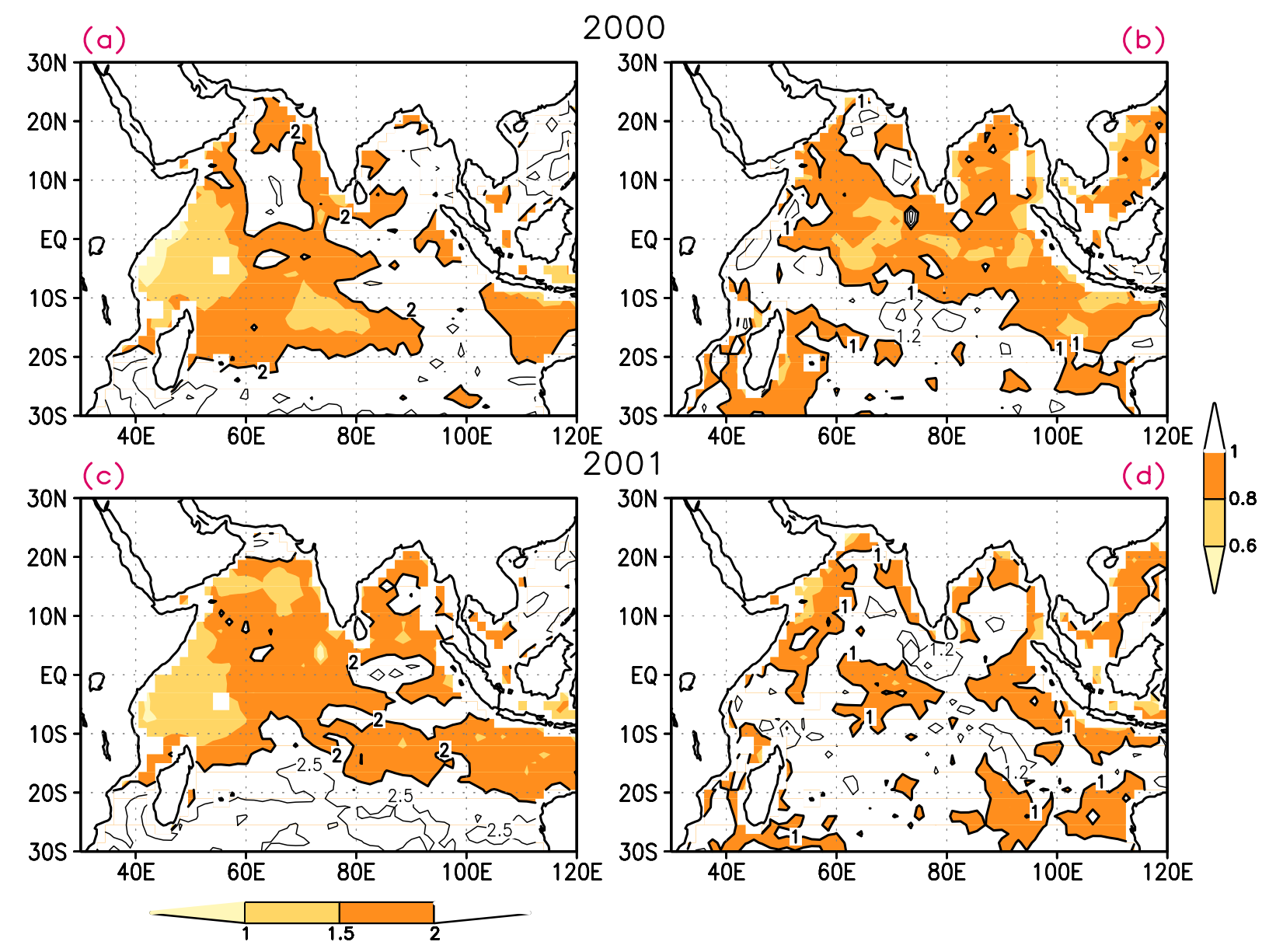

Figure 8. (a and c) Standard deviation (SD) of daily wind speed anomalies in QSCT during summer, JJAS for 2000 and 2001 and (b and $\mathbf{d}$ ) ratio of SD of NC and QSCT anomalies. S.D values less than $2 \mathrm{~ms}^{-1}$ are shaded while SD ratio less than 1.0 are shaded.

precipitation throughout the equatorial IO with largest underestimation in the eastern equatorial IO and Indonesia (figure 10). Comparison of figure 11 with figure 10 shows that the large negative bias in NC precipitation in the eastern IO is significantly reduced in 2001 not only in magnitude but also in area coverage. We also note that $\mathrm{NC}$ tends to overestimate precipitation in the western and southern equatorial IO. Both these biases in simulation of NC precipitation namely, weaker than observed precipitation in the eastern Indian Ocean and stronger than observed precipitation in the western Indian Ocean, have the potential to lead to weaker westerlies or easterly bias in the central equatorial IO. To test whether these biases in $\mathrm{NC}$ precipitation may be related to the observed wind biases in NC, a linear model of surface winds (Saji and Goswami 1996) was forced by the mean precipitation bias corresponding to each month. The model of surface winds constructed by Saji and Goswami (1996) included the effect of SST gradients in a Gill type model through a transfor- mation suggested by Neelin (1989). Our previous experiments with the model forced separately by SST gradients and precipitation heating indicate that the SST gradients contribution account for less than a quarter of the observed wind anomalies. Therefore, the influence of the SST gradients is not included in these simulations. Thus, the model is essentially a Gill model. Bimonthly mean simulated vector winds as a response to precipitation bias in 2000 are shown in figure 12 . The good correspondence between the simulated winds and the wind bias over the oceanic regions in figure 4 indicates that the precipitation bias in the $\mathrm{NC}$ analysis is indeed responsible for the easterly bias in the equatorial IO and northerly bias in the south equatorial IO during 2000. Improvement in NC surface winds during 2001 specially over the equatorial region is, therefore, essentially due to the improvement of precipitation bias in the tropical belt (figure 11).

What is responsible for improvement in the short range prediction of precipitation by $\mathrm{NC}$ dur- 


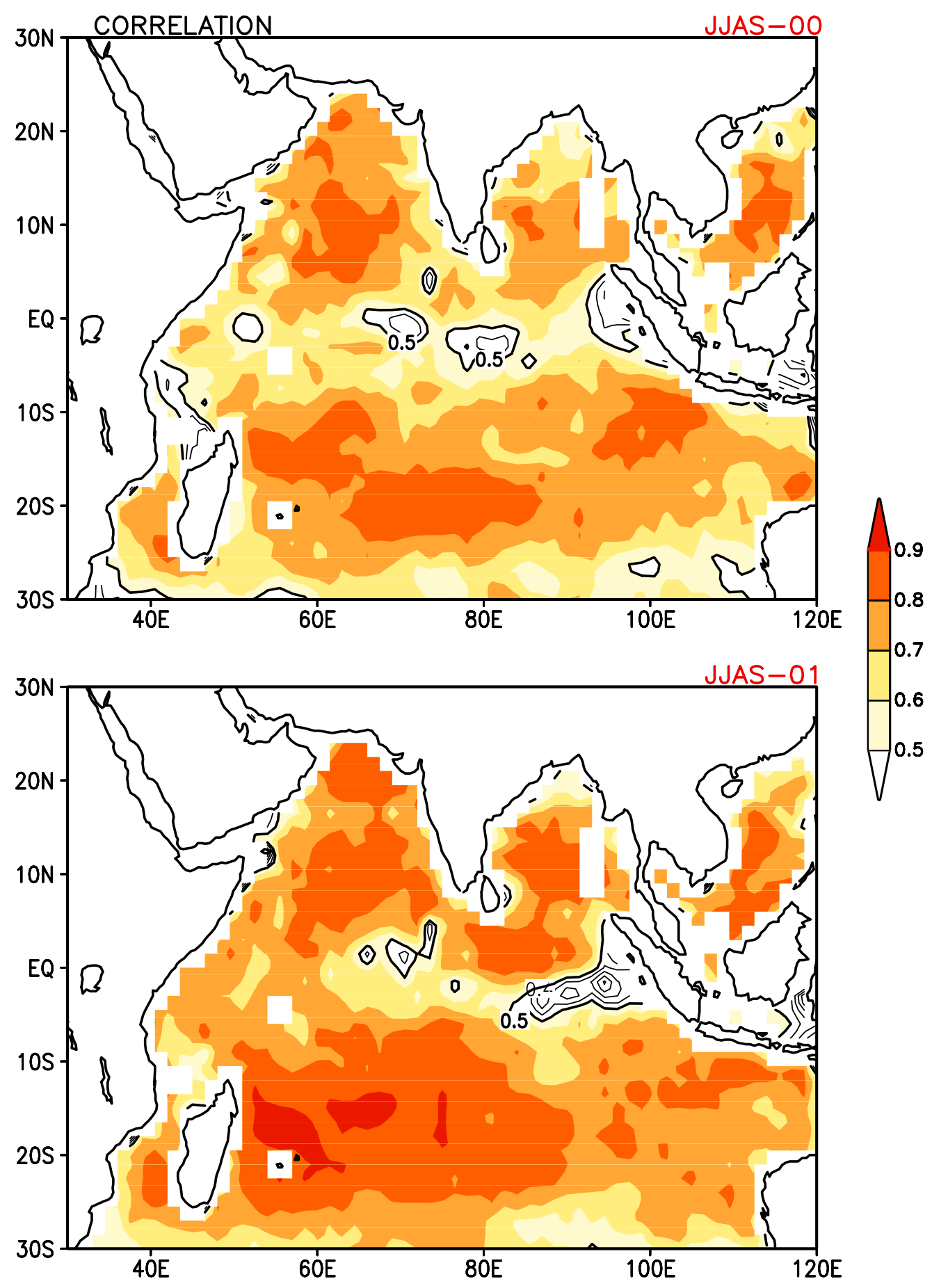

Figure 9. Temporal correlation between daily wind speed anomalies of NC and QSCT during summer (JJAS) of 2000 and 2001. Correlation greater than 0.5 are shaded.

ing 2001? While a detailed investigation of this question is beyond the scope of the present paper, we speculate on a couple of possible reasons. A major new feature introduced in January of 2001 in the NC Analysis System was the assimilation of total precipitable water from SSM/I satellite with a prescribed vertical profile. Other modification of the forecast model introduced in 2001 include introduction of a non-local PBL scheme and use of daily NCEP SST analysis instead of SST climatology. These changes seem to have overcome some of the initial spin-up related deficiency of the forecast model and resulted in a better definition of the initial precipitation field and led to improvement in 

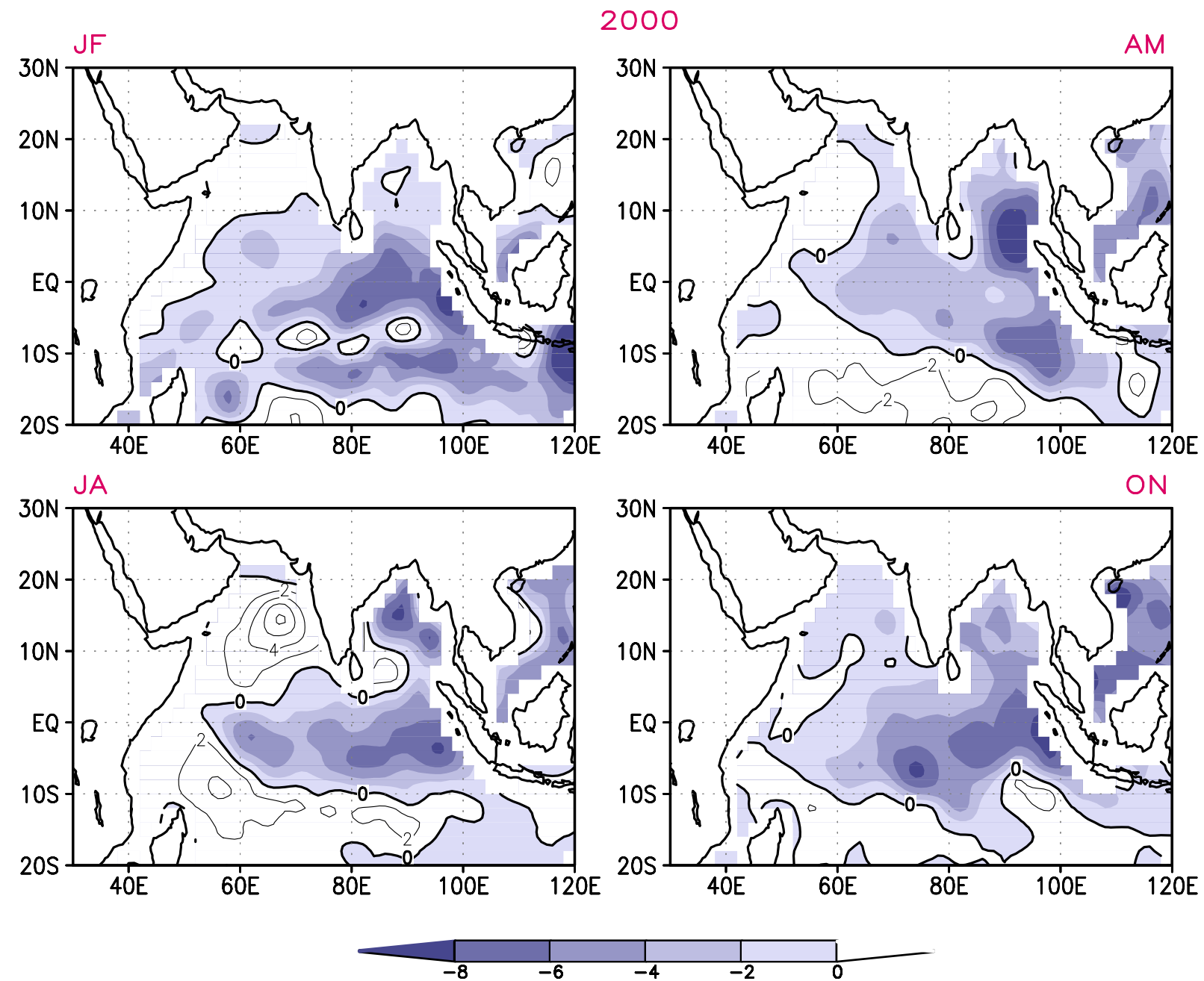

Figure 10. Bimonthly mean bias (NC-CMAP) of analyzed precipitation (mm/day) of NC compared to observations (CMAP) for the year 2000. Negative contours are shaded.

the surface winds in the equatorial region in 2001. However, we may add here that while there was clear improvement of simulation of precipitation in the equatorial region during 2001 by NC, no dramatic improvement of simulation of precipitation over the Indian continent was noticed in 2001 (not shown). Reason for this non-uniform improvement of precipitation simulation by the model is unclear to us at this point and is currently under investigation.

\section{Summary and conclusion}

Good quality high frequency surface winds in the $\mathrm{IO}$, particularly in the equatorial IO, are crucial for modeling of circulation and thermodynamics of the IO as well as for study of air-sea interaction in the region. As operational surface wind products are often used for such studies, it is important to assess the quality of such operational surface wind products. The quality of the surface wind analysis at NCMRWF is examined by comparing the surface wind analysis (NC) during 1999, 2000 and 2001 with in situ buoy measurements and satellite derived surface winds from NASA QuikSCAT satellite (QSCT). Both the zonal and meridional winds in NC are underestimated in the buoy locations during 1999 and 2000 but are closer to buoy measurements in 2001. It is shown that NC winds suffered from an easterly bias in the equatorial IO and northerly bias in the south equatorial IO during 1999 and 2000. Not only were the mean winds weaker than QSCT winds during 1999 and 2000, the amplitude of daily variability was also underestimated. In particular, the amplitude of daily variability of $\mathrm{NC}$ winds in the eastern equatorial IO was only about $60 \%$ of that of QSCT during 1999 

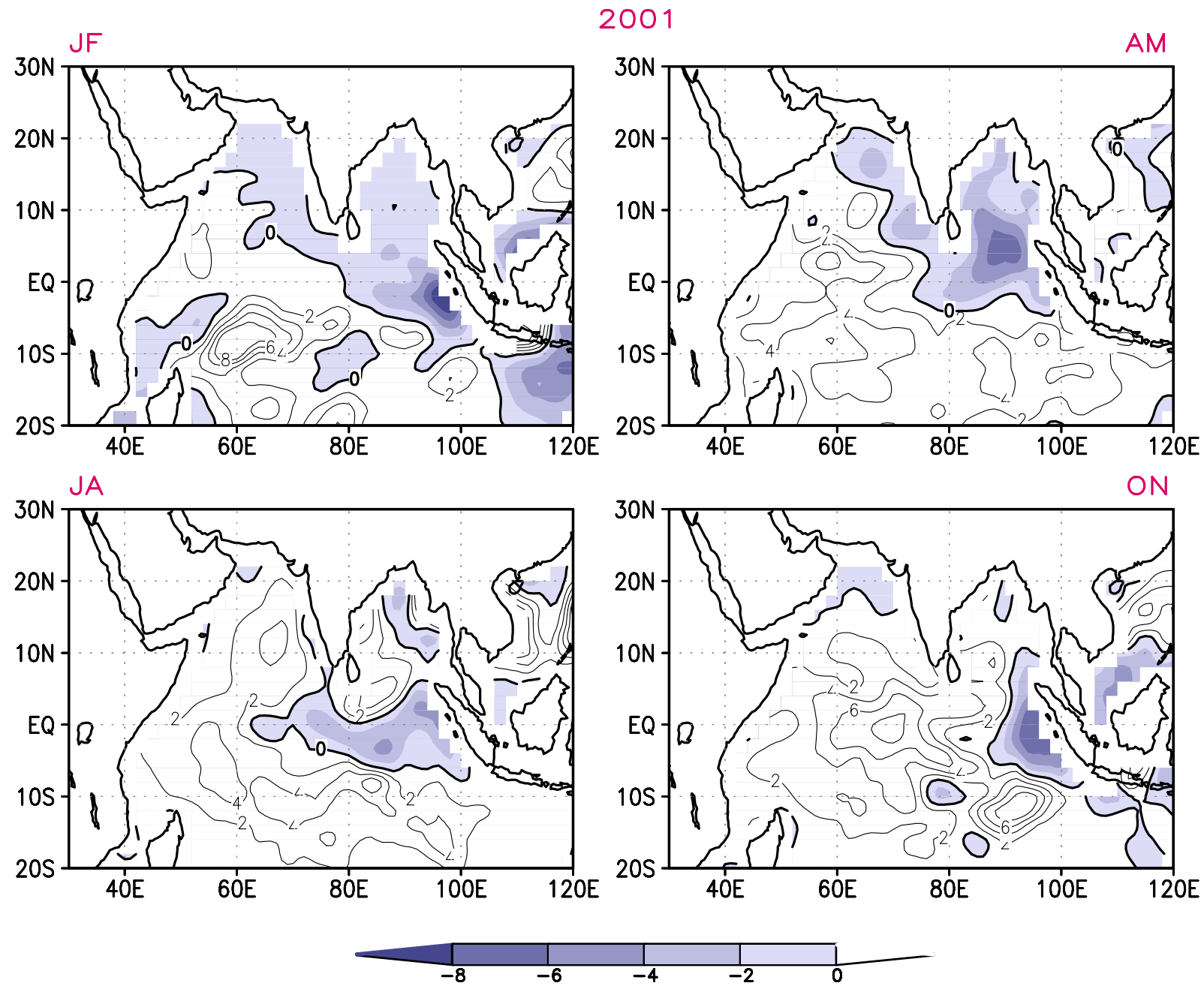

Figure 11. Same as figure 10, but for 2001.

and 2000. It is shown that the NC surface winds during 2001 are significantly improved as the difference in the mean analyzed $\mathrm{NC}$ surface winds and QSCT is considerably reduced everywhere. In particular, the difference in the equatorial IO is all but vanished. It is also shown that the amplitude of daily and intraseasonal variability is very close to that in QSCT almost everywhere. In addition, the phases of the $\mathrm{NC}$ analyzed winds match closely with those of observation (QSCT) leading to overall improvement of correlation between the two almost everywhere.

It is shown that the bias in the surface wind analysis during 1999 and 2000 was related to the bias in short range forecast of precipitation by the NC forecast model. During these two years, the NC severely underestimated precipitation in the eastern IO. Through the use of a linear model, it is shown that the precipitation bias would lead to the easterly bias in the equatorial IO and northerly bias in the south equatorial IO. The precipitation bias in $\mathrm{NC}$ in the equatorial IO is reduced to a great extent during 2001 consistent with the reduction in the wind bias. The improvement in short range forecast of precipitation by $\mathrm{NC}$ appears to be due to the assimilation of total precipitable water from SSM/I satellite since January 2001 and an improvement in the PBL scheme of the forecast model.

\section{Acknowledgements}

This work is partially supported by a grant from the Department of Ocean Development, New Delhi. We thank Dr. S V Singh and Dr. SCKar for suggestions and criticisms. B N G thanks Dr. D Sengupta for many discussions. We thank Retish Senan, D S Anitha, Prince Xavier and $\mathrm{R}$ Vinay for help in analyzing the data. 

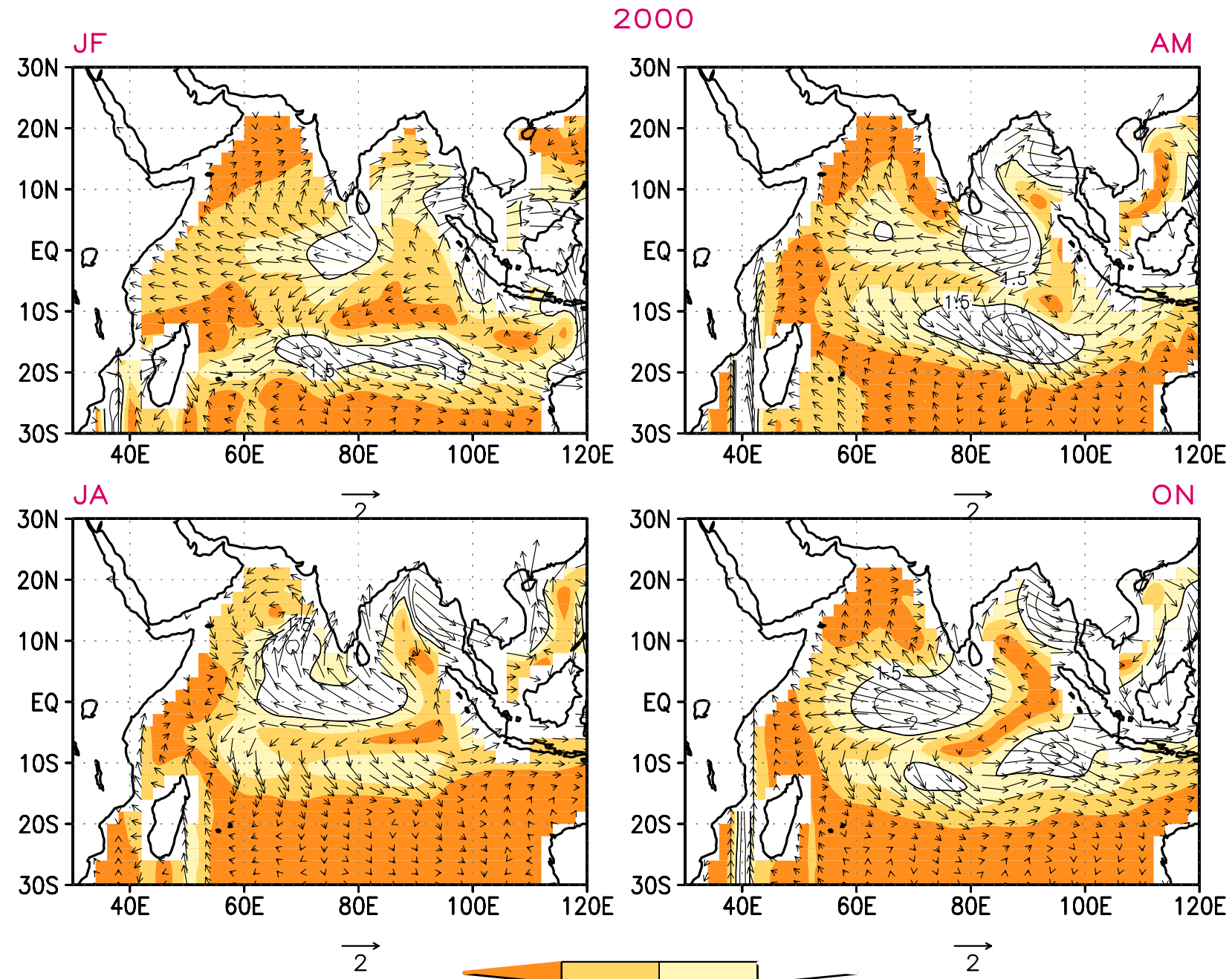

Figure 12. Bimonthly vector wind anomalies $\left(\mathrm{ms}^{-1}\right)$ and isotachs simulated by a linear model forced by precipitation biases in $\mathrm{NC}$ as shown in figure 10.

\section{References}

Chelton D B 2001 Scatterometer based assesment of surface wind field analysis from the European Center for Medium Range Forecasts. In: Proc. WCRP/SCOR Workshop on Intercomparison and Validation of Ocean-Atmosphere Flux Fields. May 21-24, MD, USA.

Chelton D B, Esbensen S K, Schlax M G, Thum N and Freilich M H 2001 Observations of coupling between surface wind stress and sea surface temperature in the eastern tropical Pacific; J. Climate 14 1479-1498

Chiang J C H, Zebiak S E and Cane M A 2001 Relative roles of elevated heating and surface temperature gradients in driving anomalous surface winds over the tropical oceans. J. Atmos. Sci. 58 1371-1394

Freilich M H, Long D G and Spenser M W 1994 SeaWinds: A scanning scatterometer for ADEOSII-Science overview; Proc. Int. Geosc. Remote Sens. Symp. Vol. II, Pasadena, Ca. IEEE No.94CH3378-7, 960-963

Gadgil S and Surendran S 1998 Monsoon precipitation in the AMIP runs; Climate Dynamics 14 659-689
Gibson J K, Kalberg P, Uppala S, Hernandez A, Namura A and Serano E 1997 ERA description, ERA project report series. ECMWF, Reading.

Gill A 1980 Some simple solutions for heat induced tropical circulation; Quart. J. Roy. Meteorol. Soc. 106 447-462

Goswami B N, Sengupta D and Suresh Kumar G 1998 Intraseasonal oscillations and interannual variability of surface winds over the Indian monsoon region; Proc. Indian Acad. Sci. (Earth Planet. Sci) 107 45-64

Goswami B N and Sengupta D 2003 A note on the deficiency of NCEP/NCAR reanalysis surface winds over the equatorial Indian Ocean; J. Geophys. Res. (Oceans), (in press)

Kalnay et al 1996 The NCEP/NCAR reanalysis project; Bull. Am. Meteorol. Soc. 77 437-471

Lindzen R S and Nigam S 1987 On the role of sea surface temperature gradients in forcing low level winds and convergence in the tropics; J. Atmos. Sci. 44 2418-2436

McCreary J P, Kundu P K and Molinari R L 1993 A numerical investigation of dynamics, thermodynamics and mixed layer processes in the Indian Ocean; Progress in Oceanography. 31 (Pergamon) 181-224 
McPhaden M J 1982 Variability in the central equatorial Indian Ocean, Part II: Oceanic heat and turbulent energy balances; J. Mar. Res. 40(2) 403-419

Murtugudde R, Seager R and Busalacchi A J 1998 Simulation of tropical oceans with an ocean GCM coupled to an atmospheric mixed layer model; J. Climate 9 1795-1815

Murtugudde R and Busalacchi A J 1999 Interannual variability of the dynamics and thermodynamics of the tropical Indian Ocean; J. Climate 12 2300-2326

Murtugudde R, McCreary Jr. J P and Busalacchi A J 2000 Oceanic processes associated with anomalous events in the Indian Ocean with relevance to 1997-1998; J. Geophy. Res. 105 3295-3306

Neelin J D 1989 On the interpretation of the Gill model; J. Atmos. Sci. 46 2466-2468

Panofsky H A and Dutton J A 1984 Atmospheric Turbulence, (New York: John Wiley and Sons) 397pp.

Parrish D F, Derber J, Purser J, Wu W and Pu Z 1997 The NCEP global analysis system: Recent improvements and future plans; J. Meteorol. Soc. Japan 75 18359-18365

Rao R R, Molinari R L and Festa J 1989 Evolution of the near surface thermal structure of the tropical Indian Ocean, Part I: Description of mean monthly mixed layer depth and surface temperature, surface current and surface meteorological fields; J. Geophys. Res. 94 10,80110,815

Rao Y R and Premkumar K 1998 A preliminary analysis of meteorological and oceanographic observations during the passage of a tropical cyclone in Bay of Bengal; NIOT technical note, NIOT-NDBP-TR-001/98

Rizvi S R H, Kamineni R and Mohanty U C 2000 Report on the assimilation of MSMR data in NCMRWF global data assimilation system; Scientific Report No. 1/2000, Department of Science and Technology, NCMRWF, Mausam Bhavan, Lodi Road, New Delhi 110003

Saji N H and Goswami B N 1996 An improved linear model of tropical surface wind variability; Quart. J. Roy. Meteorol. Soc. 122 23-53
Saji N H and Goswami B N 1997 An intercomparison of the seasonal cycle of tropical surface stress simulated by 17 GCMs; Climate Dynamics. 13 561-585

Schiller A, Godfrey J S, McIntosh P C, Meyers G and Fiedler R 2000 Interannual dynamics and thermodynamics of the Indo-Pacific Oceans; J. Phys. Ocean. 30 9871012

Senan R, Anitha D S and Sengupta D 2001 Validation of SST and wind speed from TRMM using north Indian Ocean moored buoy observations; CAOS Report 2001AS1, Centre for Atmospheric Sciences, Indian Institute of Science, Bangalore 560 012, India

Sengupta D, Joseph P, Senan R and Suresh Kumar G 1999 Validation NCEP daily surface winds over the north Indian Ocean; CAOS Report 99AS1, Centre for Atmospheric Sciences, Indian Institute of Science, Bangalore 560 012, India

Sengupta D, Goswami B N, Senan R 2001 Coherent intraseasonal oscillations of ocean and atmosphere during Asian summer monsoon; Geophys. Res. Letts. 28 41274130

Schlax M G, Chelton D B and Freilich M H 2001 Sampling errors in wind fields constructed from single and tandem scatterometer datasets; J. Atmos. Ocean. Tech. 18 10141036

Stiles B W 1999 Special wind vector data product: Direction interval retrieval with threshold nudging (DIRTH), product description version 1.1. (Pasadena, Ca. U.S.A.: Jet Propulsion Laboratory)

Vinayachandran P N, Shetye S R, Sengupta D and Gadgil S 1996 Forcing mechanisms of the Bay of Bengal Circulation; Current Science $\mathbf{7 1}$ 753-763

Wyrtki K 1973 An equatorial jet in the Indian Ocean; Science 181 262-264

Xie P P and Arkin P A 1996 Analysis of global monthly precipitation using gauge, satellite observations and numerical model precipitation; J. Climate 9 840858 